\title{
PENGEMBANGAN ALAT UKUR KECEPATAN LARI BERBASIS MICROKONTROLER DENGAN INTERFACING PERSONAL COMPUTER
}

\author{
Redi Rahmat, Agus Rusdiana, Aming Supriyatna \\ Fakultas Pendidikan Olahraga dan Kesehatan \\ Universitas Pendidikan Indonesia, Jl. Dr. Setiabudhi No. 299 Bandung \\ Em@il: Redirahmat1001193@ gmail.com
}

\begin{abstract}
Abstrak
Penelitian ini bertujuan untuk membuat software dan hardware alat ukur kecepatan lari berbasis microkontroler dengan interfacing personal computer. Penelitian ini mengunakan pendekatan metode Research and development (R\&D). Alat yang dibuat mengunakan rangkaian elekronika berbasis microkontroler, Alat ini mengunakan sensor phototransistor yang dipancari sinar laser yang fungsinya menditeksi halangan yang memotong sinar laser. Alat ini mengunakan kabel sebagai penghubung untuk transfer data, alat ini terdiri dari 8 sensor yang bisa dipasang diantara jarak 0-100 meter dengan hasil tampilan kecepatan lari dalam aplikasi Monitoring Lari Sprint 100 Meter yang dibuat mengunakan software visual basic 12. Alat ini bekerja secara otomatis ketika buzzer ditekan dan langsung menjalankan timer yang ada pada aplikasi Monitoring Lari Sprint 100 Meter, ketika atlet berlari dan memotong sinar laser di tiap sensor maka sensor akan memberikan sinyal yang memberhentikan timer yang sedang berjalan dalam aplikasi Monitoring Lari Sprint 100 Meter. Hasil tampilan waktu tempuh dan kecepatan ditampilkan di aplikasi aplikasi Monitoring Lari Sprint 100 Meter.
\end{abstract}

Kata kunci: kecepatan lari, microkontroler, hardware, software, personal computer

\section{PENDAHULUAN}

Pada abad modern ini kemajuan teknologi dalam semua bidang cabang ilmu sudah menjadi bagian yang tidak terpisahkan. Begitu juga kemajuan teknologi dalam bidang olahraga yang sudah sangat berkontribusi dalam peningkatan pembelajaran dan performa prestasi atlet. Pengunaan teknologi sebagai salah satu upaya untuk meningkatkan prestasi dalam olahraga sudah dilakukan di negaranegara maju di Asia seperti Jepang, China dan Australia.

Hal ini terbukti dengan adanya berbagai laboratorium ilmu keolahraga antara lain di Jepang ada JISS (Japan Institute of Sport Science), di Australia ada AISS (Australia
Institute of Sport Science), di China ada BISS (Bejing Iinstitute of Sport Science) dan banyak di negera lainnya, dilaboratorium ini para pakar berbagai keilmuan bersatu dan berkolaborasi untuk mengdiagnosa, mengevaluasi, memberikan masukan keilmuan kepada pelatih dan atlet tentang segala kekurangan dan kelebihan baik atlet sendiri maupun lawan yang lebih tinggi levelnya.

Kecepatan sebagai salah satu komponen kondisi fisik yang sangat penting kini pengukurannya sudah mengunakan alat-alat teknologi yang canggih. Contohnya sensor yang ditempelkan di sepatu atlet ( Foot Pod, Polar dan Suunt), Global Positioning System (GPS) dan Differential Global Positioning 
System (DGPS). selaian itu ada juga radar, photo finish, kinematic analysis, photocells dan optojump (OJ) Ales Dolenec (2009:17) yang biasanya digunakan untuk mengukur kecepatan saat berlari. Semua alat ini dibuat untuk untuk mendiagnosa, mengevaluasi dan menganalisis performa atlet untuk peningkatan prestasinya.

Pada cabang olahraga atletik yaitu lari jarak pendek peran alat-alt tersebut sangat penting untuk analisis kecepatan lari seorang atlet. Kontribusi dari analisis kecepatan lari terutama lari jarak pendek sangat diperlukan sekali untuk melakukan penelitian dan evaluasi atlet.

Sebagai contoh bentuk dari analisis lari jarak pendek diantranya adalah untuk mengetahui berapa kecepatan maksimal pelari tersebut, mengetahui dijarak keberapa kecepatan maskimal terjadi, mengetahui didetik berapa kecepatan maksimal terjadi, mengetahui daya tahan kecepatan atlet tersebut dan lain sebagainya. Berikut adalah data hasil analisis pelari tercepat di dunia Usain Bolt pelari asal Jamaika.

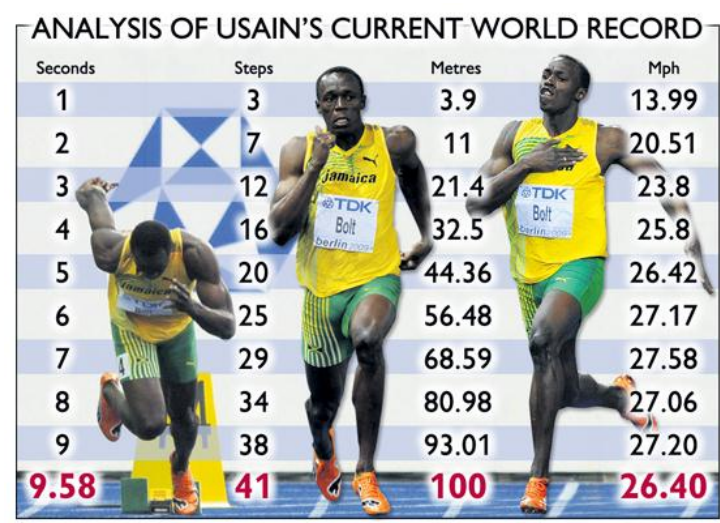

Gambar. 1 Analisis Usain Bolt

Dari hasil analisis ini kita dapat melihat bahwa seorang Usain Bolt memiliki kecepatan lari maksimal 27,58 meter/jam di jarak ke 68,58 meter pada detik ke 7. Selain ini dia juga bisa mempertahakan kecepatan rata-rata 27 meter/jam di meter ke 56-93 sehingga itu bisa dijadikan daya tahan kecepatannya. Hasil analis kecepatan lari Usain Bolt tersebut bisa dijadikan salah satu perbandingan dengan atlet pelari lainya dan dijadikan bahan evaluasi bagi Usain Bolt sendiri.

Di Indonesia sendiri perkembangan peralatan tes dan pengukuran lari masih belum berkembang, hal ini mungkin terjadi karena negara kita belum memiliki teknologi yang cukup canggih dan para pakar olahraga tidak berkolaborasi dengan pakar teknologi. Sehingga yang terjadi adalah tidak ada pemecahan secara ilmiah untuk menganalisis berbagai permasalah yang ada di olahraga. Selain itu permasalahan yang terjadi dalam pengukuran kecepatan lari saat ini masih mengunakan alat pengukur watku dan kecepatan manual yaitu dengan mengunakan stopwatch. Pengunaan stopwatch menjadi masalah dalam keakuratan data yang dimabil karena adanya perbedaan selang waktu dalam penekanan tombol. Sehingga dapat banyak menimbulkan kesalahan ( human error) karena tingkat repleks dan kepekaan manusia berbedabeda. Sehingga Perlu adanya suatu sistem alat penentu waktu dan kecepatan pelari yang otomatis (Samsul Hadi, detikSport.com).

Oleh karena itu penelitian kali ini akan membuat suatu produk alat yang berfungsi untuk menganalisis kecepatan lari. Hasil analisis ini berupa catatan waktu dan kecepatan di jarak antara 0-100 meter sesuai dengan kebutuhan peneliti, sehingga nantinya dapat mengukur kecepatan tiap lini, kecepatan maksimal, grafik kenaikan dan penurunan kecepatan secara otomatis. Dengan penelitian pengembangan alat ukur kecepatan lari berbasis microkontroler dengan interfacing personal computer peneliti akan menbuat alat yang dapat menganalisi kecepatan lari.

\section{METODE}

Metode penelitian Research and Development (R\&D) adalah metode penelitian yang digunakan untuk menghasilkan produk tertentu dan menguji keefektifan produk tersebut. Hasil akhir penelitian ini akan menghasilkan produk alat ukur kecepatan lari berbasis microkontroler dengan interfacing personal computer. 


\section{HASIL DAN PEMBAHASAN}

Produk Pengembangan Alat Ukur Kecepatan Lari Berbasis Microkontroler dengan Interfacing Personal Computer dapat dilihat pada gambar $2-7$.

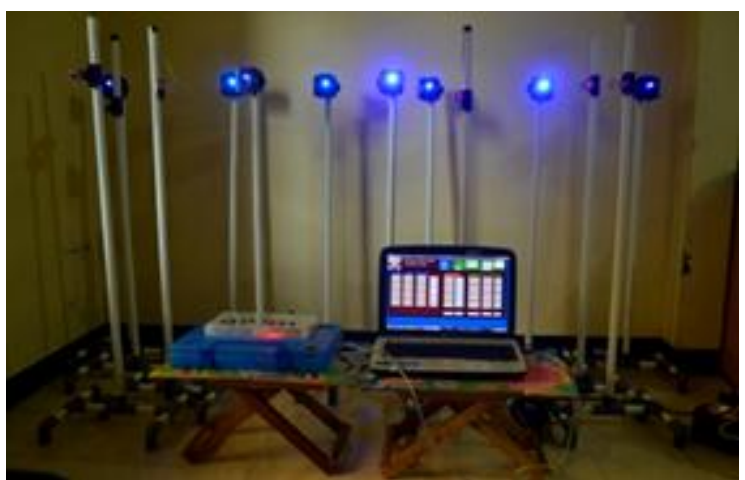

Gambar 2. Semua Komponen Alat ukur kecepatan lari berbasis mikrokontroler dengan interfacing personal computer

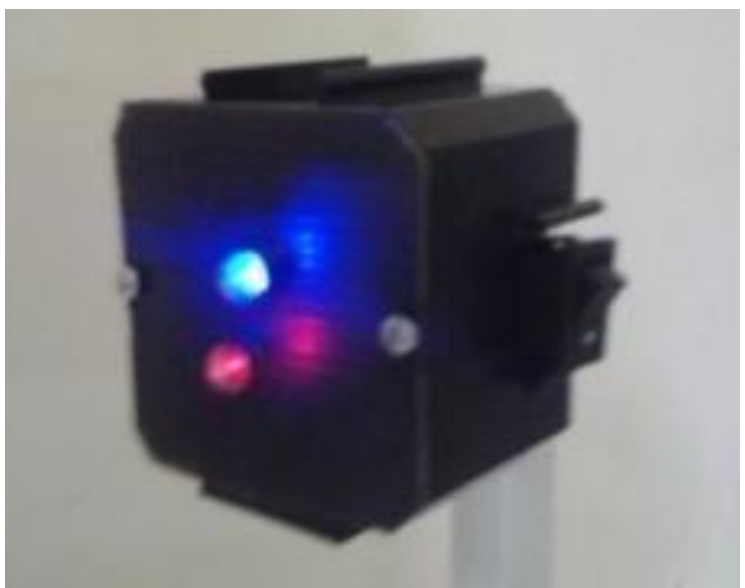

Gambar 3. Sensor Phototransistor

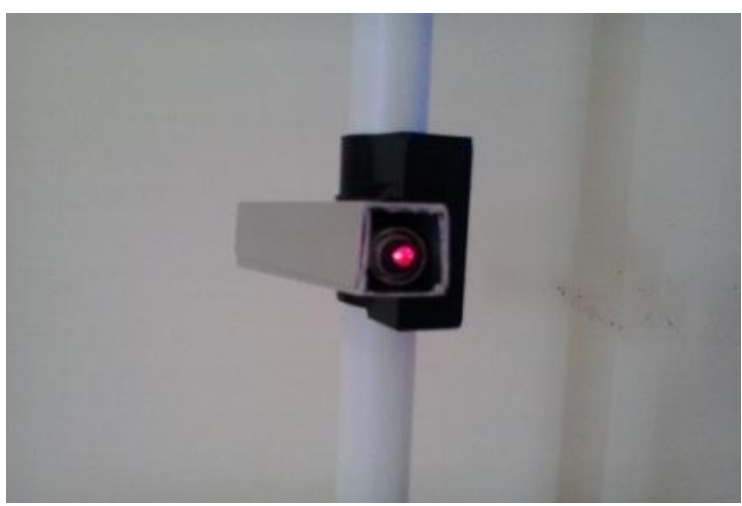

Gambar 4 Rangkaian Laser

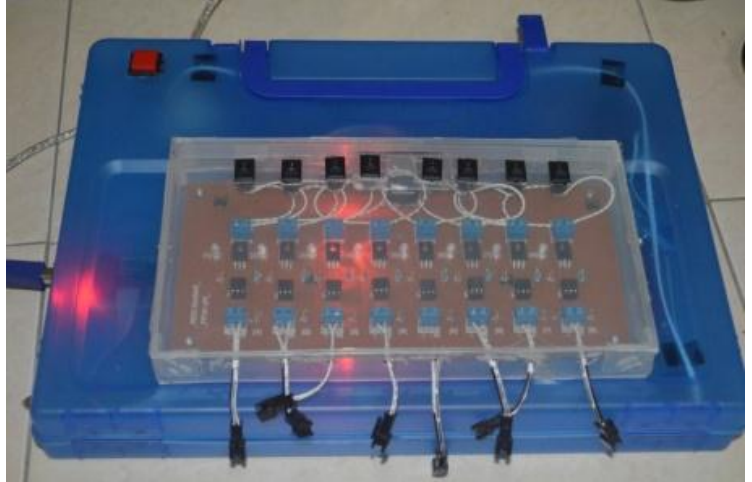

Gambar 5. Rangkaian Microkontroler dan LED Indikator

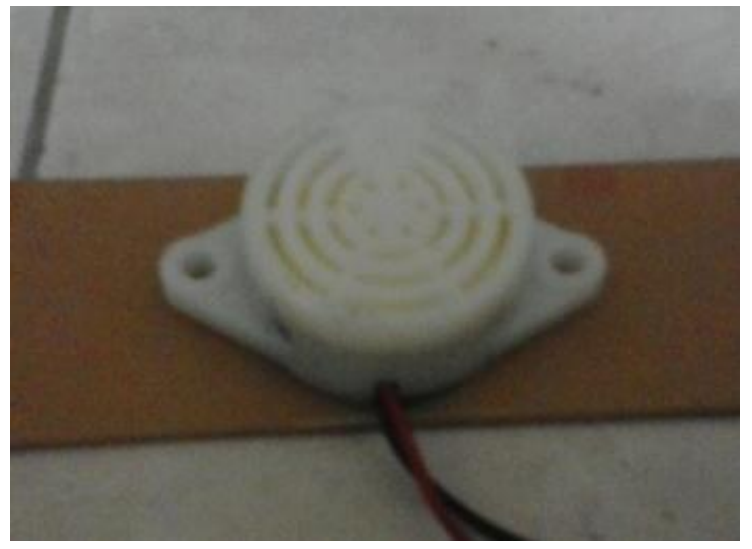

Gambar 6. Buzzer

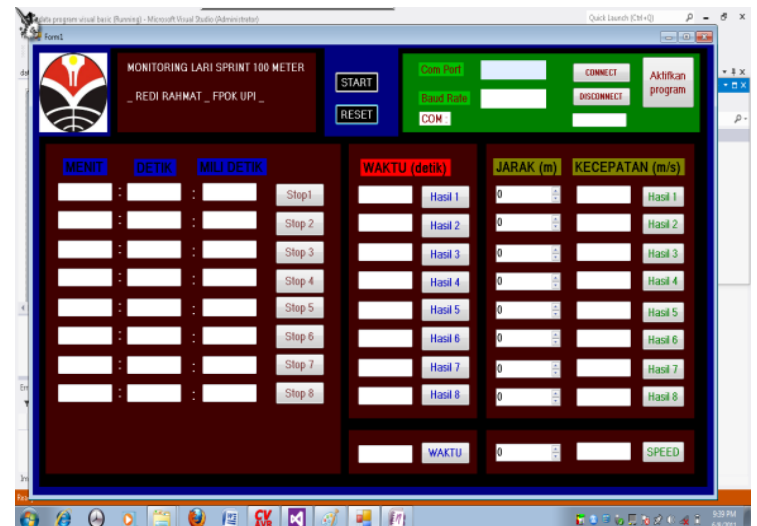

Gambar 7. Tampilan Software di Personal Computer

Alat ini akan bekerja secara otomatis setiap tombol running ditekan satu kali. Kemudian ketika tombol running ditekan maka buzzer akan berbunyi dan menandakan atlet untuk mulai berlari. Dengan berbunyinya buzzer maka timer atau stopwatch akan berjalan. Setiap sensor yang terpasang tersentuh dengan kata lain sinyal laser terpotong maka secara 
otomatis waktu akan berhenti. Setelah atlet berlari sampai ke garis finish software dikomputer akan menampilkan hasil catatan waktu lari dan kecepatannya dari titip start sampaifinish

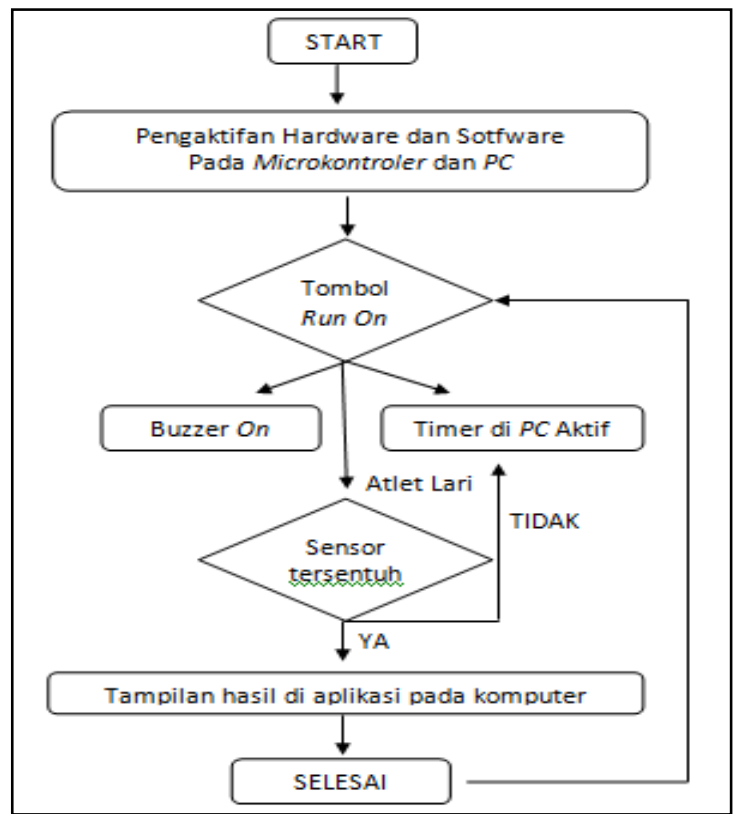

Gambar 8. Diagram Kerja Alat

Hasil Uji Coba Alat Ukur Kecepatan Lari Berbasis Mikrokontroler Dengan Interfacing Personal Computer. Uji coba dilakukan dengan memasang semua perangkat yang ada dalam alat ukur kecepatan lari berbasis microkontroler dengan interfacing personal computer.

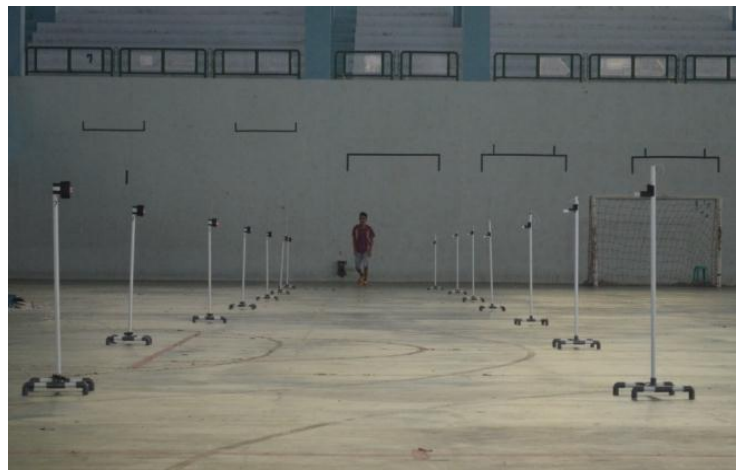

Gambar 9. Sensor Selesai Dipasang di Lintasan Lari

Pada uji coba kali ini peneliti melakukan pengukuran kecepatan pada jarak 40 meter. Sebanyak 8 buah sensor dipasang pada setiap jarak 5 meter untuk mengetahui kecepatan lari atlet setiap 5 meternya. Yang nanti hasilnya akan ditampilkan dalam aplikasi yang dibuat di personal computer

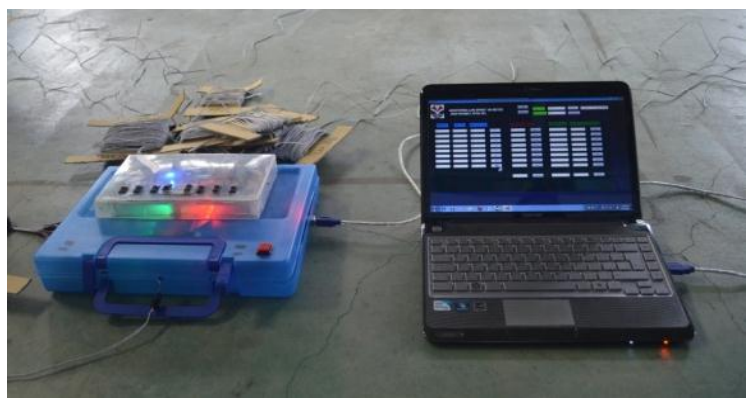

Gambar 10. Pemasangan Rangkaian Microkontroler ke Aplikasi Monitoring Sprint di Personal Komputer

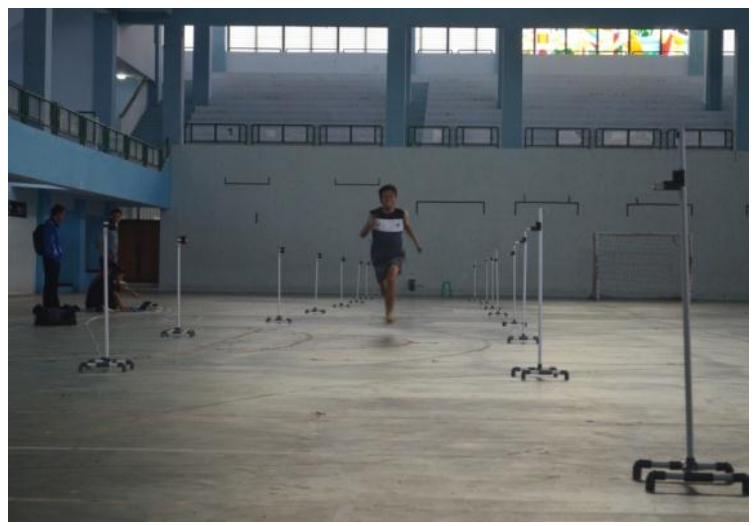

Gambar 4.18 Pelari Sedang Melakukan Percobaan Alat

Tabel 1. Hasil Percobaan 1

\begin{tabular}{|c|c|c|c|}
\hline $\begin{array}{c}\text { Jarak } \\
\text { (meter) }\end{array}$ & $\begin{array}{c}\text { Waktu } \\
\text { Tempuh } \\
\text { (detik) }\end{array}$ & $\begin{array}{l}\text { Waktu } \\
\text { Tempuh } \\
\text { / } 5 \mathrm{~m} \\
\text { (detik) }\end{array}$ & $\begin{array}{c}\text { Kecepatan } \\
/ 5 \mathrm{~m} \\
(\mathrm{~m} / \mathrm{s})\end{array}$ \\
\hline 5 & 1.60 & 1.6 & 3.125 \\
\hline 10 & 2.33 & 0.73 & 6.849 \\
\hline 15 & 3.15 & 0.82 & 6.097 \\
\hline 20 & 3.90 & 0.75 & 6.666 \\
\hline 25 & 4.61 & 0.72 & 6.944 \\
\hline 30 & 5.38 & 0.76 & 6.578 \\
\hline 35 & 6.11 & 0.74 & 6.756 \\
\hline 40 & 6.98 & 0.87 & 5.747 \\
\hline \multicolumn{2}{|c|}{ Total waktu } & \multicolumn{2}{|c|}{6.98 detik } \\
\hline \multicolumn{2}{|c|}{ Rata-Rata Kecepatan } & \multicolumn{2}{|c|}{$5.722 \mathrm{~m} / \mathrm{s}$} \\
\hline \multicolumn{2}{|c|}{ Kecepatan Maksimal } & \multicolumn{2}{|c|}{$6.944 \mathrm{~m} / \mathrm{s}$} \\
\hline \multicolumn{2}{|c|}{$\begin{array}{l}\text { Jarak Kecepatan } \\
\text { Maksimal }\end{array}$} & \multicolumn{2}{|c|}{ Pada jarak 25 meter } \\
\hline
\end{tabular}

Tabel 2. Hasil Percobaan 2 


\begin{tabular}{|c|c|c|c|}
\hline $\begin{array}{c}\text { Jarak } \\
\text { (meter) }\end{array}$ & $\begin{array}{l}\text { Waktu } \\
\text { Tempuh } \\
\text { (detik) }\end{array}$ & $\begin{array}{c}\text { Waktu } \\
\text { Tempuh/ } \\
5 \mathrm{~m} \\
\text { (detik) }\end{array}$ & $\begin{array}{c}\text { Kecepatan/ } \\
5 \mathrm{~m} \\
\mathrm{~m} / \mathrm{s}\end{array}$ \\
\hline 5 & 1.32 & 1.32 & 3.787 \\
\hline 10 & 2.34 & 0.71 & 7.042 \\
\hline 15 & 2.80 & 0.77 & 6.493 \\
\hline 20 & 3.50 & 0.7 & 7.142 \\
\hline 25 & 4.20 & 0.7 & 7.142 \\
\hline 30 & 4.90 & 0.7 & 7.142 \\
\hline 35 & 5.60 & 0.69 & 7.142 \\
\hline 40 & 6.35 & 0.75 & 6.66 \\
\hline \multicolumn{2}{|c|}{ Total waktu } & \multicolumn{2}{|c|}{6.35 detik } \\
\hline \multicolumn{2}{|c|}{ Rata-Rata Kecepatan } & \multicolumn{2}{|c|}{$6.229 \mathrm{~m} / \mathrm{s}$} \\
\hline \multicolumn{2}{|c|}{ Kecepatan Maksimal } & \multicolumn{2}{|c|}{$7.142 \mathrm{~m} / \mathrm{s}$} \\
\hline \multicolumn{2}{|c|}{$\begin{array}{l}\text { Jarak Kecepatan } \\
\text { Maksimal }\end{array}$} & \multicolumn{2}{|c|}{ Pada jarak 20 meter } \\
\hline
\end{tabular}

Tabel 3. Hasil Percobaan 3

\begin{tabular}{|c|c|c|c|}
\hline $\begin{array}{c}\text { Jarak } \\
\text { (meter) }\end{array}$ & $\begin{array}{l}\text { Waktu } \\
\text { Tempuh } \\
\text { (detik) }\end{array}$ & $\begin{array}{l}\text { Waktu } \\
\text { Tempuh/ } \\
5 \text { m } \\
\text { (detik) }\end{array}$ & $\begin{array}{c}\text { Kecepatan/ } \\
5 \mathrm{~m} \\
\mathrm{~m} / \mathrm{s}\end{array}$ \\
\hline 5 & 1.13 & 1.13 & 4.424 \\
\hline 10 & 1.83 & 0.71 & 7.04 \\
\hline 15 & 2.55 & 0.71 & 7.04 \\
\hline 20 & 3.20 & 0.65 & 7.69 \\
\hline 25 & 3.96 & 0.67 & 7.46 \\
\hline 30 & 4.56 & 0.7 & 7.14 \\
\hline 35 & 5.33 & 0.76 & 6.57 \\
\hline 40 & 6.10 & 0.87 & 5.743 \\
\hline \multicolumn{2}{|c|}{ Total waktu } & \multicolumn{2}{|c|}{6.10 detik } \\
\hline \multicolumn{2}{|c|}{ Rata-Rata Kecepatan } & \multicolumn{2}{|c|}{$6.557 \mathrm{~m} / \mathrm{s}$} \\
\hline \multicolumn{2}{|c|}{ Kecepatan Maksimal } & \multicolumn{2}{|c|}{$7.69 \mathrm{~m} / \mathrm{s}$} \\
\hline \multicolumn{2}{|c|}{$\begin{array}{l}\text { Jarak Kecepatan } \\
\text { Maksimal }\end{array}$} & \multicolumn{2}{|c|}{ Pada jarak 20 meter } \\
\hline
\end{tabular}

Alat ukur kecepatan lari berbasis mikrokontroler dengan interfacing personal computer dapat bekerja menghitung waktu dan kecepatan lari 0-100 meter. Pemasangan sensor dapat dilakukan sesuai kebutuhan analilis dari peneliti misal di setiap 10 meter, 5 meter atau jarak yang lainya sesuai kebutuhan peneliti. Hasil kecepatan lari ditampilkan dalam computer yang sudah terinstal dengan aplikasi monitoring sprint.

Alat ukur kecepatan lari berbasis mikrokontroler dengan interfacing personal computer memiliki beberapa fungsi untuk analisis kecepatan yaitu: (1) waktu tempuh dan kecepatan lari; (2) waktu tempuh dan kecepatan tiap lari lini; (3) kecepatan maksimal; (4) daya tahan kecepatan; (5) analisis karakter kecepatan pelari.

\section{KESIMPULAN}

Alat ukur kecepatan lari berbasis microkontroler dengan interfacing personal computer dibuat dengan rangkaian elekronik berbasis microkontroler. Alat ini mengunakan sesor phototransistor yang akan menditeksi halangan atau pelari yang melewati sensor tersebut. Alat ini mengunakan kabel sebagai fungsi komunikasi transfer data. Tampilan haril lari mengunakan aplikasi monitoring sprint yang dibuat mengunanan software visual basic 12.

Alat ukur kecepatan lari berbasis microkontroler dengan interfacing personal computer bekerja untuk mengukur kecepatan lari tiap lini 0-100 meter. Pemasangan 8 buah sensor dipasang sesuai jarak yang dibutuhkan untuk analisis peneliti. Kecepatan pelari ditampilkan dalam komputer yang sudah terinstal dengan aplikasi monitoring sprint.

\section{DAFTAR PUSTAKA}

Budiharto, Widodo. 2005. Panduan Lengkap Belajar Mikrokontroller Perancangan dan Aplikasi Mikrokontroller. Jakarta : Gramedia.Putra,

Dolanec Ales. 2009. Comparison Of Photocell and optojump Mentsruments of Maximum Runing Velocity. Kinesiologia Slovenica, 15,2,16-24.

Hendrayana. (2007). Bermain Atletik. Bandung: Universitas Pendidikan Indonesia.

Imanudin, Iman. (2008:66). Ilmu kepelatihan olahraga. Bandung: Universitas Pendidikan Indonesia. 
Johan, dkk. (2012:). Pengaruh latihan lompat kijang terhadap kecepatan. Journal of sport sciences and fitness, 1 (1), hlm. 18-21.

Samsul Hadi (2008). Kesalahan ( Human Error ). Tersedia di http://www.detikSport.com

Sanchez Natalia dkk (2007) SpeedMed: device for measuring velocity in track sports. Revista Ingerieria Biomedica. No 1 hal, 33-37

Setiawan Aji dkk. 2011. Alat Pengukur Kecepatan Lari Berbasis Mikrokontroler. Yogyakarta : UNY

Sidik, Z. D. (2010). Belajar dan Melatih Atletik. Bandung: PT Remaja Rosdakarya.

Sidik, Z. D. (2008). Pembinaan Kondisi Fisik (Dasar dan Lanjutan). Bandung: PT Remaja Rosdakarya.

Sidik, Z. D. (2013). Dampak penerapan "Complex Training" Terhadap peningkatan kemampuan dinamis anaerobik. JUARA. Jurnal Iptek Olahraga, 1 (1), hlm. 7-33.

Sudira Putu (2005) Modul Bahan Ajar Mikrokontroller. Hlm 82-156.

Sugiyono (2011). Metode Penelitian Kuantitatif, Kualitatif dan R\&D. Bandung: ALFABETA.

Prasetia Rena, Widodo Catur (2004). Teori dan Praktek Interfacing Port Pararel dan Port Serial Komputer dengan Visual Basic 6.0. Yogyakarta: ANDI

Winendra, dkk. (2008). Atletik (lari, lompat, lempar). Yogyakarta: Pustaka Insan Madani.

Yuherdi dkk. (2013). Korelasi waktu reaksi dan akselerasi terhadap prestasi lari 100 meter mahasiswa putra semester II program studi PENJASKESREK FKIP Universitas Riau. Jurnal primary program studi pendidikan guru sekolah dasar fakultas keguruan dan ilmu pendidikan universitas riau, 2 (2), hlm. 34-41 